\title{
STANDARDIZATION OF THE MEASUREMENT OF TRANSFER FACTOR (DIFFUSING CAPACITY)
}

\author{
REPORT WORKING PARTY \\ STANDARDIZATION OF LUNG FUNCTION TESTS \\ EUROPEAN COMMUNITY FOR STEEL AND COAL
}

\author{
OFFICIAL STATEMENT OF THE EUROPEAN RESPIRATORY SOCIETY \\ h. \\ J.E. Cotes, D.J. Chinn, Ph.H.Ruanjer, J. Roca, J.-C. Yernault
}

\section{CONTENTS}

1 Introduction

1.1 What is being measured.

41

1.2 Some points of terminology .............................................. 42

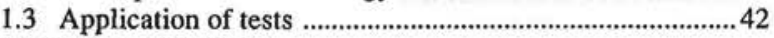

2 Derivation of indices

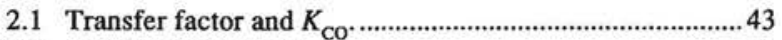

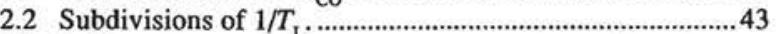

3 The indices

3.1 Transfer factor $\left(T_{L}\right)$

3.1.1 $T_{1, \text { co.sb }}:$ Single breathholding method ........................4 44

3.1.2 $T_{1,00, s}:$ Single expiration method ...............................44

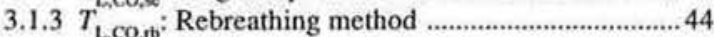

3.1.4 $T^{\prime}, 0^{\circ}$ : Steady state method .....................................44

3.1.5 $T_{1,02, s p}$ : Riley-Lilienthal method .............................44

$3.1 .6 T_{102, s^{\prime}}: V^{\prime} / Q^{\prime}$ method .............................................44

3.1.7 $T$.02, : Single breath method ....................................45

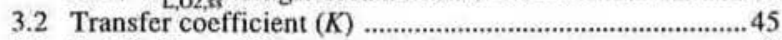

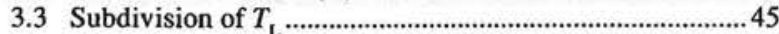

3.3.1 Diffusing capacity of the alveolar capillary membrane $\left(D_{m}\right)$....................................................45

3.3.2 Volume of blood in alveolar capillaries $\left(Q_{\mathrm{c}}\right) \ldots \ldots . .45$

3.3.3 Reaction rate of carbon monoxide with oxyhaemoglobin $(\theta)$.

4 Conditions of measurement

5 Measurement of $T$, method

5.1 Procedure
5.2 Gas analysis 45

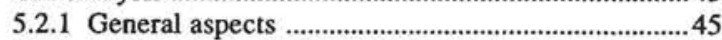

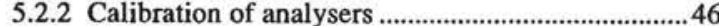

5.3 The breathholding manoeuvre ….........................................46

5.4 The alveolar volume 47

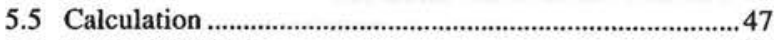

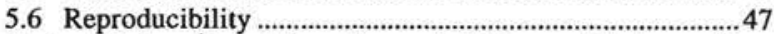

6 Factors to be allowed for when calculating and interpreting the result

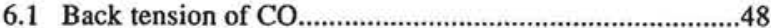

6.1.1 In mixed venous blood ............................................... 48

6.1.2 In pulmonary capillary blood ...................................48

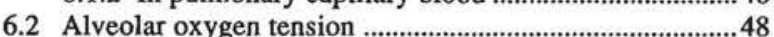

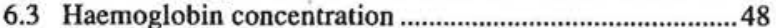

6.4 Age, stature and body muscle ...........................................48

6.5 Habitual activity during adolescence ......................4. 48

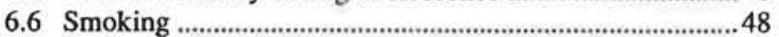

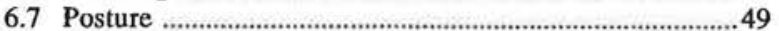

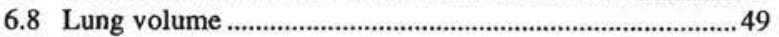

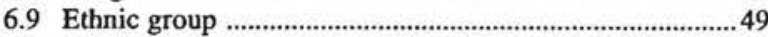

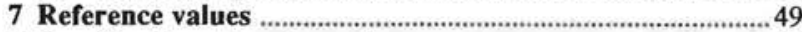

8 Specification of equipment ......................................................49

9 Future research

9.1 Improvement in methodology ...........................................5 50

9.2 Inter-laboratory differences

9.3 Additional reference values .................................................50

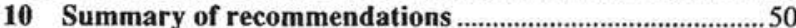

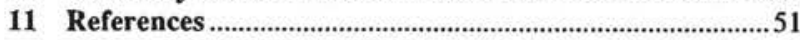

\section{Introduction}

\subsection{What is being measured}

The lung is the organ of external respiration for the exchange of oxygen and carbon dioxide between the blood and the surrounding air. The stages in the process of gas transfer include:

1. Ventilation of the airways and some air spaces by bulk flow of gas;
2. Mixing and diffusion of gases in the alveolar ducts, air sacs and alveoli;

3. Transfer of gases across the gaseous to liquid interface of the alveolar membrane;

4. Mixing and diffusion in the lung parenchyma and alveolar capillary plasma;

5. Chemical reaction with constituents of blood;

6. Circulation of blood between the pulmonary and systemic vascular beds.

The capacity of the lung to exchange gas is determined by the structural and functional dimensions of these 
processes. The structural dimensions include the lung volume, the path length for diffusion in the gas phase, the thickness and area of the alveolar capillary membrane including any effects of airway closure, and the volume of blood in capillaries supplying alveoli which are ventilated. The principal functional dimensions are the absolute levels of ventilation and perfusion and the uniformity of their distribution with respect to both each other and the diffusion characteristics of the membrane. Other functional dimensions are the quantity of haemoglobin in the alveolar capillaries, the composition of the alveolar gas, the gas tensions in blood entering the alveolar capillaries, the rates of chemical reaction with haemoglobin and of dissociation of the compound so formed, the transit time of blood through that part of the pulmonary vascular bed which exchanges gas with the alveoli and the slope of the relevant haemoglobin dissociation curve. The latter is a function of the temperature of the lung and the prevailing levels of oxygen, carbon dioxide, hydrogen ions and 2,3-diphosphoglycerate; many of these variables are dependent on the level of metabolism and change in relation to exercise.

The gas exchanging characteristics of the lung parenchyma, including the factors which contribute to the reaction rate of gases with haemoglobin, are assessed by measurement of the transfer factor for the lung. The test gas can be oxygen but because oxyhaemoglobin dissociates readily, carbon monoxide (which has a higher affinity for haemoglobin) is commonly used instead. Nitric oxide can also be used, but the method is still in process of development $[1,2]$ and its independence of the effects of NO on the pulmonary circulation [3] appears not to have been confirmed.

\subsection{Some points of terminology}

The transfer factor is altematively called the diffusing capacity. However, the latter term is potentially misleading for two reasons. First, the index is affected by many other factors in addition to the diffusing characteristics of the lung. Second, the index is positively correlated with the metabolic rate; thus, since the measurement is usually made at rest or during submaximal exercise, the index is also submaximal and not a capacity. The term transfer factor reflects this heterogeneity and is appropriate, but the gas which is used and the locations between which the transfer is measured should be specified. The term commonly describes the rate of transfer of $\mathrm{O}_{2}$ or $\mathrm{CO}$ between the alveoli and the red cells in the alveolar capillaries. The units of transfer are quantity of substance per unit time per unit pressure difference (or gradient) between the two sites $\left(e . g . \mathrm{mmol} \cdot \mathrm{min}^{-1} \cdot \mathrm{kPa}^{-1}\right)$; these are the dimensions of a conductance. The term diffusive conductance has therefore been proposed but, whilst an improvement on diffusing capacity, it still has some of its disadvantages.

\subsection{Application of tests}

The measurement of transfer factor $\left(T_{\mathrm{L}}\right)$ usually constitutes the second stage in the assessment of lung function
Table 1. - Interstitial lung diseases which are associated with a reduced transfer factor. (Reproduced from [9] with permission).

\section{A Systemic diseases which can involve the lung}

Sarcoidosis, beryllium disease

Disorders of connective tissue, including progressive systemic sclerosis, rheumatoid arthritis, lupus erythematosus, polyarteritis nodosa

Coeliac disease

Schistosomiasis (bilharzia)

Xanthomatoses, including eosinophilic granuloma

Disseminated tuberculosis, carcinomatosis, neurofibromatosis and other conditions

Chronic interstitial oedema (from left ventricular failure, hexamethonium, uraemia, etc.)

B Diseases which primarily involve the lung

Interstitial pneumonitis, including Hamman Rich syndrome (diffuse fibrosing alveolitis)

Extrinsic allergic alveolitis, including farmer's lung, bird handler's lung, suberosis, etc.

Nitrous fume exposure (e.g. silo-filler's lung)

Virus pneumonia

Drug sensitivity, e.g. to nitrofurantoin, bleomycin, busulphan

Chronic interstitial fibrosis, including cases of interstitial pneumonitis, asbestosis, talcosis, hard metal disease, acute silicosis, radiation fibrosis

Bronchiolar or alveolar cell carcinoma, lymphomatous infiltrate

Alveolar proteinosis and micro-lithiasis, pulmonary muscular hyperplasia, leiomyomatosis and other conditions

after the performance of spirometry and measurement of lung volume [4]. The transfer factor is used mainly for the diagnosis and clinical management of persons with suspected or confirmed disease of the parenchyma of the lung, for example generalised emphysema, interstitial fibrosis or extrinsic allergic alveolitis. In disseminated emphysema. The transfer factor and $K_{\mathrm{CO}}\left(T_{\mathrm{L}} / V_{\mathrm{A}}\right)$ are reduced mainly because of destruction of alveolar capillary membrane, reducing the surface available for gas exchange [5]. In the case of the transfer factor the reduction can be offset by an increase in total lung capacity. The transfer factor is normal or slightly reduced in the presence of narrowing of lung airways ( $\S 6.8$ ) and can be increased in asthma, particularly when the latter is associated with an increase in total lung capacity [6]. For the diagnosis of emphysema the transfer factor is reported to be more informative than the lung compliance [7] and as informative as CT scans [8]. The transfer factor is reduced in almost all disorders of the lung parenchyma including widespread granulomas, interstitial exudates, inflammatory exudates, extensive pneumoconiosis and disseminated carcinomas. These categories embrace a very large number of conditions (table 1); in all of them the transfer factor can contribute to diagnosis and be used for monitoring progress. An intrapulmonary haemorrhage (e.g. Goodpasture's syndrome) can increase the transfer factor for carbon monoxide $\left(T_{\mathrm{L}, \mathrm{CO}, \mathrm{sb}}\right)$ because 
the additional haemoglobin is usually accessible to and combines with some carbon monoxide in the test gas [10]. On this account $T_{\mathrm{L}, \mathrm{CO}, \mathrm{sb}}$ can contribute to diagnosis and to monitoring progress. The measurement is used in the investigation of pulmonary vascular disorders including pulmonary hypertension.

The interpretation of the result should take into account the many additional factors which can influence the transfer factor ( $\$ 6)$. In an occupational context the most relevant is smoking, whilst in a clinical context the most relevant are the haemoglobin concentration, which may need to be allowed for ( $\S 6.3$ ), and the alveolar volume (§ 6.8). The latter relationship can be exploited for the diagnosis of interstitial fibrosis in the presence of diffuse pleural thickening such as can occur as a result of exposure to asbestos. In both conditions the transfer factor is reduced, but whereas the $K_{\mathrm{CO}}$ is usually reduced when there is asbestosis, it is increased when the inspiratory capacity is reduced by diffuse pleural thickening without much involvement of the lung parenchyma ( $\$ 6.8)$. The test can also form part of the assessment of respiratory disability and can contribute to the indirect assessment of exercise capacity $[11,12]$. It is used for studying aspects of respiratory physiology.

The measurement of transfer factor is usually made in the lung function laboratory when it can be accompanied by a separate determination of total lung capacity; for respiratory surveys the separate lung volume is usually omitted ( $\$ 5.4$ ). The survey is likely to be of persons exposed to asbestos [13, 14] or who may have extrinsic allergic alveolitis, for example arable farm workers in areas of high rain fall [15], mushroom growers [16], those who handle birds [17] or are at risk from a contaminated humidifier or epoxy resins $[18,19]$. However, even for these applications the test should usually be reserved for subjects with respiratory symptoms.

\section{$2 \quad$ Derivation of indices}

\section{$2.1 \quad$ Transfer factor and $K_{\mathrm{Co}}$}

The transfer factor is obtained from measurements of the rate of uptake of the indicator gas $\left(\mathrm{O}_{2}\right.$ or $\left.\mathrm{CO}\right)$ and the transfer gradient, which is the partial pressure difference for the indicator gas between the alveoli and the pulmonary capillary red cells (or plasma). Then:

$$
T_{\mathrm{L}}=\text { rate of gas uptake/transfer gradient }
$$

e.g. for carbon monoxide

$$
T_{\mathrm{L}}=n_{\mathrm{CO}}^{\prime} \cdot\left(P_{\mathrm{A}, \mathrm{CO}}-P_{\mathrm{c}, \mathrm{CO}}\right)^{-1}
$$

where $T_{\mathrm{L}}$ is transfer factor, $n_{\mathrm{CO}}^{\prime}$ is the rate of uptake of carbon monoxide $\left(\mathrm{mmol} \cdot \mathrm{min}^{-1}\right)$ and $P_{\mathrm{CO}}$ is the partial pressure of carbon monoxide in A (alveolar gas) and $\mathrm{c}$ (pulmonary capillary red cells).

The transfer factor is positively correlated with the lung volume at which the measurement is made and can be represented as the product of the alveolar volume $\left(V_{\mathrm{A}}, l\right.$
BTPS) and the transfer coefficient of the lung $(K)$ for the relevant gas. Thus, for carbon monoxide:

$$
T_{\mathrm{L}}=V_{\mathrm{A}} \cdot K_{\mathrm{CO}}\left(\mathrm{mmol} \cdot \mathrm{min}^{-1} \cdot \mathrm{kPa}^{-1}\right)
$$

or

$$
K_{\mathrm{CO}}=T_{\mathrm{L}} N_{\mathrm{A}}\left(\mathrm{mmol} \cdot \mathrm{min}^{-1} \cdot \mathrm{kPa}^{-1} \cdot l^{-1}\right)
$$

The transfer coefficient was introduced by Krogh as the permeability constant of the lung in absolute units of volume per volume per atmosphere per minute, but these units are less convenient than those given above. In addition the term permeability constant has the same limitations as diffusing capacity.

\subsection{Subdivisions of $1 / T_{\mathrm{L}}$}

Carbon monoxide and nitric oxide combine rapidly with haemoglobin, but the compounds so formed do not readily dissociate. In these circumstances (unlike with oxygen which dissociates freely) the transfer factor can be partitioned into two component conductances, of which one reflects the diffusion characteristics of the alveolar capillary membrane and the other the overall reaction of the test gas with haemoglobin. The latter can be represented as the product of the chemical reaction rate in suitable units and the volume of blood in the alveolar capillaries. The reciprocals of these quantities can be considered as resistances in series. Hence:

$$
1 / T_{\mathrm{L}}=1 / D_{\mathrm{m}}+1 /\left(\theta \cdot Q_{\mathrm{c}}\right)
$$

where $T_{\mathrm{L}}, D_{\mathrm{m}}$ and $Q_{\mathrm{c}}$ are respectively the transfer factor, the diffusing capacity of the alveolar capillary membrane and the volume of pulmonary blood with which exchange of gas takes place; $\theta$ is the reaction rate for the test gas with haemoglobin. The reaction rate for carbon monoxide $\left(\theta_{\mathrm{CO}}\right)$ is negatively correlated with the prevailing oxygen partial pressure. This feature was used by ROUGHTON and Forster [20] as a basis for measuring $D_{\mathrm{m}}$ and $Q_{c}$. Transfer factor is measured at two levels of alveolar oxygen tension (usually approximately 15 and 80 $\mathrm{kPa}$ ) each of which has its own value for $\theta$; these values and those for $T_{\mathrm{L}}$ at each oxygen tension are substituted in eq. 5 , i.e.:

$$
\begin{aligned}
& 1 / T_{\mathrm{L} 1}=1 / D_{\mathrm{m}}+1 /\left(\theta_{1} \cdot Q_{\mathrm{c}}\right) \\
& 1 / T_{\mathrm{L} 2}=1 / D_{\mathrm{m}}+1 /\left(\theta_{2} \cdot Q_{\mathrm{c}}\right)
\end{aligned}
$$

These equations are then solved for $D_{\mathrm{m}}$ and $Q_{c}$. The method has the advantage of relative simplicity but the disadvantage that the functional dimensions of the lungs as they affect gas exchange are assumed not to change between breathholding with air and with $80-85 \%$ oxygen; this assumption could be incorrect in patients with uneven lung function. Alternatively the partitioning can be done by measuring the transfer factors for carbon monoxide and nitric oxide concurrently. The method again yields two simultaneous equations but this time the 
variables are on the one hand $T_{\mathrm{LCO}}$ and $T_{\mathrm{LNO}}$ and on the other $\theta_{\mathrm{CO}}$ and $\theta_{\mathrm{NO}}$ [21]. Both methods depend on the values used for the reaction rates being reasonably accurate: this may not be the case at present [22]. However, despite these problems the measurement of $D_{\mathrm{m}}$ and $Q_{c}$ has illuminated factors which contribute to the transfer factor in a number of circumstances [§ 6]. It has also provided a valid method for standardising the transfer factor for haemoglobin concentration which would otherwise affect the result when the concentration is abnormal (§ 6.3).

\section{The indices}

\subsection{Transfer factor $\left(T_{L}\right)$}

\subsection{1 $T_{\mathrm{L} \text { CO,sb }} ;$ single breathholding method [23]}

The subject inhales and holds in the lung for a minimum of $8-10 \mathrm{~s}$ a nearly vital capacity breath of test gas which includes carbon monoxide in low concentration, and helium or other inert gas not normally present in the body. During the subsequent exhalation, a sample of alveolar gas is obtained and analysed for both gases. The concentration of the helium is lower than that inspired by an amount which reflects the dilution of the test gas into that already present in the lung. The same dilution factor is applied to the carbon monoxide in the test gas in order to obtain the initial alveolar concentration: the final alveolar concentration is that in the alveolar sample. The two concentrations together with the time of breathholding and the alveolar volume during breathholding are used for the calculation of the transfer factor. The method of calculation, including the derivation of alveolar volume, is given in $\S 5$. The result is usually considered to reflect the gas exchanging characteristics of the lung parenchyma; however, it is affected by uneven distribution of lung function when the alveolar volume is used. $T_{\mathrm{L}, \mathrm{CO}, \mathrm{sb}}$ is measured in most lung function laboratories and is recommended. It can be adapted for use with subjects who are HIV positive. In one laboratory this is done by incorporating a bacterial filter in the mouthpiece and using $2 \%$ glutaraldehyde to sterilise the apparatus [24].

\subsection{2 $T_{\mathrm{L}, \mathrm{Co}, \mathrm{se}}$; single expiration method [25]}

This index is a variant of that obtained by the breathholding method which is described above. The alveolar concentrations of carbon monoxide are obtained during a single expiration by use of a rapid analyser for carbon monoxide. The method avoids difficulties associated with defining the initial alveolar concentration of carbon monoxide, deciding on the volume and position of sampling, and making allowance for the times of inspiration and sample collection. However, the result is influenced by the previous volume history of the lung. In addition, the equipment is expensive and the method presents technical difficulties which have still to be investigated systematically.

\subsection{3 $T_{\mathrm{L}, \mathrm{CO}, \mathrm{s}}$; rebreathing method $[26,27]$}

The index is obtained from measurements made during a period of rebreathing from a bag. The rebreathing promotes mixing of gas. This minimises the effects of uneven distribution of lung function compared with the breathholding method. The test can be adapted for use at the bedside but some patients find the rebreathing uncomfortable; the calculation can be tedious and the results are not interchangeable with those by the breathholding method. The method is not recommended for routine use.

\subsection{4 $T_{\mathrm{L}, \mathrm{CO}, \mathrm{ss}}$; steady state method [28]}

The calculation is that given in equation 2 . The uptake of cartion monoxide is obtained under steady state conditions from measurements of ventilation minute volume and the concentrations of carbon monoxide in the inspired and the mixed expired gas. The partial pressure of carbon monoxide in the alveolar gas is obtained either by analysis of end tidal gas for carbon monoxide or by calculation from the pressure in the mixed expired gas and the deadspace to tidal volume ratio measured for carbon dioxide. The latter is obtained from the $\mathrm{CO}_{2}$ tensions in the mixed expired gas and either the end tidal gas [28] or the arterial blood [29] or the mixed venous blood measured indirectly [30].

The index provides an overall measure of lung function, including uneven distribution as well as gas transfer. It is more reproducible when measured on exercise than at rest, but even so may yield falsely high as well as falsely low results. The uptake of $\mathrm{CO}$ under steady state conditions can also be expressed in terms of the inspired and mixed expired gas concentrations as the fractional $\mathrm{CO}$ uptake. This index usually reflects the steady state transfer factor, but is more susceptible to changes in minute ventilation. The method is mainly used in circumstances when the subject cannot perform the single breathholding method satisfactorily.

\subsection{5 $T_{\mathrm{L}, 02, \mathrm{ss}}$; Riley-Lilienthal method [31]}

The index is obtained from the uptake of oxygen and the mean tensions of oxygen in the alveolar gas and the pulmonary capillary blood. A trial and error procedure is used to partition the alveolar-arterial oxygen tension difference into two components which reflect respectively unevenlung function and imperfect gas transfer. This requires arterial cannulation or ear oximetry [32], exercise and breathing a low oxygen mixture. The method is demanding and embraces simplifying assumptions which re not strictly correct. However, the result is both more stable and more meaningful than the complexity of the procedure would suggest. The method is of historic importance but of limited applicability.

\subsection{6 $T_{\mathrm{LO}_{\mathrm{ss}}} ; V_{\mathrm{A}}^{\prime} / Q_{\mathrm{c}}^{\prime}$ method [33]}

This method, which was introduced by West, Wagner and colleagues, resembles the previous one in partitioning the alveolar-arterial oxygen tension difference into 
two components. Here it is done by estimating the component due to uneven lung function from the distribution of ventilation-perfusion ratios throughout the lung. The distribution is assessed using the multiple inert gas elimination technique [34]. The method is technically demanding but has the merit that it can be applied during moderately heavy exercise.

\subsection{7 $T_{\mathrm{L}, 02, \mathrm{ss}} ;$ single breath method [35]}

At present, this is a research method, but it may have clinical application.

\subsection{Transfer coefficient $\left(K_{\mathrm{CO}}\right)$}

The index is derived using equation 4 and expressed in $\mathrm{mmol} \cdot \mathrm{min}^{-1} \cdot \mathrm{kPa}^{-1} \cdot l^{-1}$. It is negatively correlated with the lung volume at which the measurement is made and is therefore neither a constant nor interchangeable with the transfer factor. In addition the relationship is non-linear. The association between $K_{\mathrm{CO}}$ and lung volume can lead to difficulty in interpretation, particularly during childhood and adolescence, in non-Caucasians ( $\S 6.9$ ) and in patients in whom the total lung capacity is reduced. However, in the latter circumstance the $K_{\mathrm{Co}}$ can contribute additional information, for example in the diagnosis of patients with a history of exposure to asbestos who have either or both diffuse pleural thickening and diffuse pulmonary fibrosis ( $\S 6.8,[36])$. The transfer coefficient is also referred to as $T_{\mathrm{L}} / V_{\mathrm{A}}$ or as Krogh factor; use of the latter term should be limited to circumstances when the result is in absolute units ( $\S 2$ above).

\subsection{Subdivisions of $1 / T_{\mathrm{L}, \mathrm{CO}}$}

\subsubsection{Diffusing capacity of the alveolar capillary membrane $\left(D_{\mathrm{m}}\right)$}

$D_{\mathrm{m}}$ is nearly proportional to the lung volume and reflects the area and thickness of the alveolar capillary membrane. The numerical value is very dependent on the value chosen for $\theta$ ( $\$ 2.2)$. Any mathematical treatment of the index should be performed using the reciprocal form in which the index is derived (i.e. $1 / D_{\mathrm{m}}$, equation 7). The index appears to contribute more to models of the function of the lung than to clinical practice.

\subsubsection{Volume of blood in the alveolar capillaries $\left(Q_{\mathrm{c}}\right)$} $Q_{\text {c }}$ is negatively correlated with the lung volume and is affected by any condition which leads to redistribution of the blood volume within the body. Like $D_{m}$, this index should be analysed mathematically in the reciprocal form (i.e. $1 / Q_{\mathrm{c}}$ ). Its main usefulness is in pulmonary embolism, mitral stenosis and other conditions of the pulmonary circulation.

\subsubsection{Reaction rate of carbon monoxide with oxyhae- $\operatorname{moglobin}(\theta)$.}

The derivation of $D_{\mathrm{m}}$ and $Q_{\mathrm{c}}$ depends on knowing the relationship of $\theta$ to the prevailing partial pressure of oxygen, also the partition coefficient between the membrane and the interior of the erythrocyte. Information on both aspects is incomplete [22].

\section{$4 T_{\mathrm{L}, \mathrm{CO}, \mathrm{sb}}$ : Conditions of measurement}

The volume of blood in the lung capillaries is affected by anything which influences the distribution of blood volume throughout the body, including cardiac output (hence recent or present activity), time with respect to meals, posture, state of cutaneous vasomotor tone (hence ambient and deep body temperature), alveolar pressure, etc. The diffusing capacity of the alveolar capillary membrane is affected by the lung volume during the measurement ardd $\theta$ is affected by the tension of oxygen in the alveolar capillaries. The diffusion gradient is affected by carbon monoxide which is present in the blood ( $\$ 6.1$ ). The conditions of the measurement of $T_{\mathrm{L}, \mathrm{CO}, \mathrm{sb}}$ should be standardized with respect to all these variables. Thus the result should ideally be obtained in the middle of the morning or afternoon (i.e. 2-4 h after a light meal) with the subject in a relaxed but upright seated posture which has been maintained for $10 \mathrm{~min}$. The subject should remain seated between tests. He or she should preferably not have smoked on the day. The ambient temperature should be in the range $16-23^{\circ} \mathrm{C}$. The subject should not have breathed oxygen (e.g. for measurement of the single breath nitrogen index) immediately before the test procedure.

\section{Measurement of $T_{\mathrm{LCO}, \mathrm{sb}}$ and sub- divisions by breathholding method}

\subsection{Procedure}

An outline of the method is given in $\S 3.1$. In more detail, the seated subject, who is fitted with a noseclip, first exhales to residual volume and subsequently inhales a vital capacity breath of a He-CO mixture. After breathholding at total lung capacity ( $\$ 5.3$ ), the subject exhales again and the expired volume is divided into an initial dead space washout and an alveolar sample. The latter portion is collected in a bag which has been previously evacuated. The alveolar sample is led through absorbers for water vapour and $\mathrm{CO}_{2}$, to the $\mathrm{CO}$ and $\mathrm{He}$ analysers on line with a flow meter and a pump. The analysers have been previously adjusted to give a zero reading on room air at atmospheric pressure, and the bag is emptied through the system at a rate of about $0.5 l \cdot \mathrm{min}^{-1}$ until the analyser gives a stable reading, which is finally made at zero flow.

\subsection{Gas analysis}

\subsubsection{General aspects}

The inspired gas mixture is usually carbon monoxide in the fractional concentration of 0.003 (i.e. $F_{\mathrm{I}, \mathrm{CO}}=$ 0.003 ), helium in the concentration range 0.02 to 0.14 , 
depending on the characteristics of the analyser, oxygen $\left(F_{\mathrm{I}, \mathrm{O} 2}=0.17\right)$ with the remainder nitrogen including the rare gases $(\S 6.2)$. The requisite concentrations of oxygen and nitrogen can sometimes be achieved at minimal cost by appropriate dilution with air or a gas mixture containing carbon monoxide in helium. Lower concentrations of carbon monoxide and other inert gases (e.g. neon) may also be employed. Carbon monoxide is usually analysed by an infrared absorption method, helium by its thermal conductivity (katharometer) and oxygen by a paramagnetic analyser. The latter is only required if it is intended to measure $D_{\mathrm{m}}$ and $Q_{\mathrm{c}}$. Gas chromatography and, for the analysis of oxygen and the inert gas, mass spectrometry can also be used.

The accuracy of the gas analysis should be to $1 \%$ of the initial concentration. The response time of the instruments is not important. In the case of carbon monoxide and helium, error may occur due to the interfering effects of oxygen, carbon dioxide, water vapour or other gases (for example $\mathrm{C}_{2} \mathrm{H}_{2}$ or $\mathrm{N}_{2} \mathrm{O}$ used for concurrent measurement of cardiac output). These gases can be absorbed prior to passage of the gas sample through the helium and carbon monoxide analysers. Both gases are thereby concentrated to the same extent so their ratio, which is used in the calculation of $T_{\mathrm{L}}$ (equation 8) is unaffected and no correction is required. It is however needed when the helium concentration is used in the calculation of effective alveolar volume (equation 9). Alternatively, the analysis may be performed by mass spectrometry or gas chromatography.

\subsubsection{Calibration of analysers}

Helium. The linearity of the helium analyser and volume of the deadspace of the closed circuit spirometer can be assessed by serial dilution of a mixture of helium in air contained in the spirometer. The analyser is zeroed on room air. The closed circuit is filled with the inspirate gas mixture, the bell is depressed and the initial helium concentration is noted. Air from a cylinder is added to the spirometer in half of one litre steps and each new helium concentration is noted. The reciprocal of the helium concentration is plotted against the volume added; the relationship should be linear [9]. A curvilinear relationship is evidence that the helium analyser is alinear. Carbon monoxide. The linearity of the carbon monoxide analyser can be checked using a helium analyser which has been shown to be linear. The analyser under test is zeroed on room air which is passed through the instrument at the recommended flow (usually $0.5 l \cdot \mathrm{min}^{-1}$ ). The inspiratory bag is filled with the transfer factor test mixture and this is similarly analysed for carbon monoxide and helium. The analyses are repeated after successive dilutions of the inspirate with air from a cylinder; the concentrations of helium and carbon monoxide (expressed as ratios of their respective initial values) are plotted against one another. The relationship should be linear.

Oxygen. The linearity of the oxygen analyser can be checked with "white-spot" nitrogen which is used both to confirm the zero point and to dilute the transfer test gas

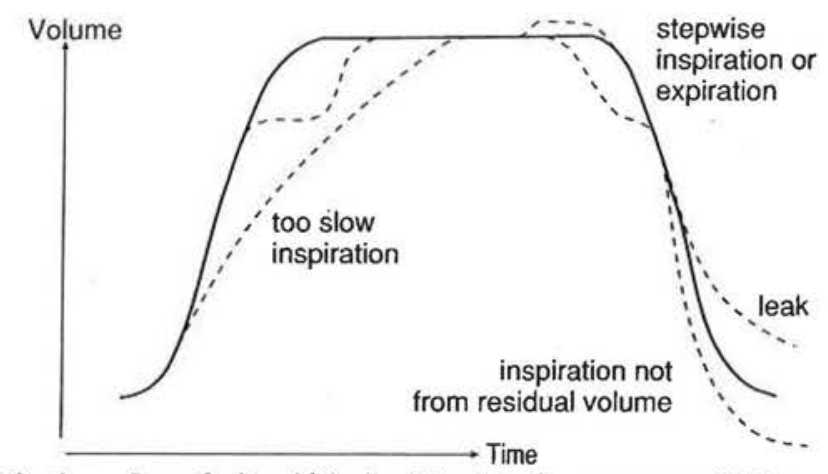

Fig. 1. - Some faults which should lead to the measurement being rejected on technical grounds. (From [9], with permission).

mixture prior to the analysis of helium; the procedure is a similar to that for carbon monoxide which is described above. The helium meter is slightly sensitive to oxygen, which is normally compensated for by using an appropriate electrical circuit. The adequacy of the compensation can be checked using helium in air and in oxygen.

\subsection{The breathholding manoeuvre}

The inspiration of test gas should start from the residual volume and continue to within $5 \%$, or at the most $10 \%$, of total lung capacity. The duration of inspiration should preferably be less than $2.5 \mathrm{~s}$ but up to $4.0 \mathrm{~s}$ is acceptable [37]. The volume of sample should be in the range $0.6-$ $0.9 l$, and the time of sample collection should not exceed $3 \mathrm{~s}$. Some unacceptable features which should lead to the manoeuvre being repeated are shown in figure 1 . The intrapulmonary pressure during breathholding should be at or near to atmospheric pressure.

The beginning and end of inspiration can be defined either visually or by extrapolating the central linear part of the inspired volume-time curve (fig. 1) [38]. The time of breathholding should take into account inspiration and expiration, including the time when the gas sample for analysis is being collected [39]. This can be done empirically. The effective duration of breathholding is normally taken to include two-thirds of the time of inspiration and the time of expiration up to half-way through the period of sample collection [40]. The alternative of taking the time from the start of inspiration to the beginning of sample collection [41] is widely used [37], but it can yield an artificially low time and hence an unduly high transfer factor in patients with airflow limitation [42]. A spirogram of the breathholding manoeuvre is shown in fig. 2. Conventions which underestimate the effective time of inspiration and make no allowance for the time of sample collection $[43,44]$ should not be used.

\subsection{The alveolar volume}

The lung volume during breathholding can be obtained in one of two ways. The first entails adding to the inspired volume of test gas the residual volume measured by the closed circuit helium dilution method. Both gas 
Table 2. - Reproducibility of single measurements of transfer factor by single breath method.

\begin{tabular}{|c|c|c|c|}
\hline Initial value & $\begin{array}{r}T_{\mathrm{L}, \text { eff }} \\
14.0\end{array}$ & $\begin{array}{r}V_{\text {A,eff }} \\
7.61\end{array}$ & $\begin{array}{l}K_{\mathrm{CO}} \\
1.82\end{array}$ \\
\hline \multicolumn{4}{|c|}{ Within sessions (2nd determination compared with first) } \\
\hline trend $(\%)$ & $-2.6^{8}$ & -0.6 & -2.1 \\
\hline $\mathrm{v}(\%)$ & 4.4 & 3.0 & 4.2 \\
\hline \multicolumn{4}{|c|}{ During day (afternoon compared with morning) } \\
\hline trend $(\%)$ & $-2.0^{8}$ & $1.4^{\S}$ & -3.5 \\
\hline $\mathrm{v}(\%)$ & 5.1 & 3.5 & 5.1 \\
\hline \multicolumn{4}{|c|}{ During week (Friday compared with Tuesday) } \\
\hline trend (\%) & $3.9^{\S}$ & $3.5^{\S}$ & 0.2 \\
\hline $\mathrm{v}(\%)$ & 5.5 & 3.6 & S.7 \\
\hline
\end{tabular}

volumes should be expressed at BTPS bearing in mind that the humidity of the test inspirate may initially be zero. The alveolar volume so measured is designated $V_{\mathrm{A}}$. The residual volume can also be measured by whole body plethysmography. An account of these methods is given in [45]. Alternatively, the effective alveolar volume can be measured by the dilution in the lung of the helium present in the initial breath of test gas [46]. When this is done, allowance should be made for the effects upon the helium concentration of the deadspace of the equipment used for collecting the sample of alveolar gas and for the carbon dioxide which is absorbed prior to analysis. The estimated anatomical deadspace $(\S 5.5)$ plus the deadspace of the apparatus should be subtracted from the inspired gas volume before the latter is multiplied by the ratio of the inspired to corrected alveolar helium concentrations to obtain the effective alveolar volume $\left(V_{\text {A,eff }}\right)$. The calculation is given in $\S 5.5$ below. In most circumstances either $V_{\mathrm{A}}$ or $V_{\mathrm{A} \text {, fff }}$ can be used. However, for patients with airflow limitation the use of $V_{\mathrm{A} \text {,eff }}$ can yield relatively low values for the transfer factor $T_{\mathrm{L}, \text { eff }}$ If the flow limitation is reversible the values can sometimes be increased to approach those of $T_{\mathrm{L}}$ by making the measurement after administration of a bronchodilator drug [42] (§ 6.8). The lung volume which is used should be indicated.

\subsection{Calculation}

The transfer factor is routinely calculated using a simplified relationship: this incorporates the exponential decline during breathholding of the alveolar carbon monoxide concentration and the derivation of the latter at time zero from the inspired concentration of $\mathrm{CO}$ and the helium concentrations which are given above. The tension of carbon monoxide in the pulmonary capillary blood (equation 2) is assumed to be zero. Then:

$$
T_{\mathrm{L}, \mathrm{CO}, \mathrm{sb}}=\mathrm{b} \cdot V_{\mathrm{A}} \cdot t^{-1} \cdot \log _{10}\left(F_{\mathrm{L}, \mathrm{CO}} \cdot F_{\mathrm{A}, \mathrm{He}} \cdot F_{\mathrm{A}, \mathrm{CO}}{ }^{-1} \cdot F_{\mathrm{I}, \mathrm{He}}{ }^{-1}\right)
$$

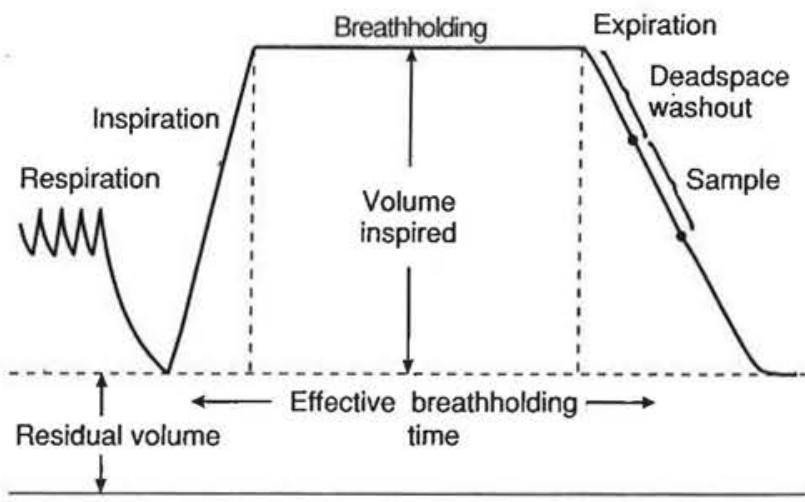

Fig. 2. - Spirogram illustrating the procedure for determining the transfer facto \& for the lung by the single breath (breathholding) method. The subject breathes out to residual volume, inhales a vital capacity breath of the test gas, holds the breath for $8 \mathrm{~s}$, then exhales slowly; after the exhalation of $0.75 l$ (range $0.7-1.0 \mathrm{l}$ ) a sample of 0.5 or $1.0 \mathrm{l}$ of alveolar gas is collected for analysis. (From [9], with permisson).

where $t$ is time of breathholding in seconds, $F_{\mathrm{A}}$ is alveolar concentration (of helium and carbon monoxide) and the other terms are as defined above. The coefficient b is dictated by the dimensions of the component terms, including the use for convenience of decimal logarithms. Assuming a normal barometric pressure, b in SI units has the value 53.6, and in traditional units 160 . Its derivation is given elsewhere [9]. $V_{\mathrm{A}}$ is alveolar volume ( $l$ BTPS); it is measured in one of the ways given in $\S 5.4$.

When effective alveolar volume is used it is calculated as follows:

$$
V_{\mathrm{A}, \mathrm{eff}}=\mathrm{K} \cdot\left(V_{\mathrm{I}}-V_{\mathrm{D}, \text { an }}-V_{\mathrm{ds}}\right) \cdot F_{1} / F_{2}
$$

where $V_{\mathrm{I}}=$ inhaled volume, $V_{\mathrm{D}_{\text {an }}}=$ anatomic deadspace, $V_{\mathrm{ds}}=$ instrumental dead space, $\mathrm{F}_{1}=$ helium concentration in inspired gas, and $F_{2}=$ helium concentration in the expired sample; it is corrected for contamination by air in the deadspace of the bag $\left(V_{\mathrm{D}, \mathrm{bag}}\right)$ by multiplying the actually measured helium concentration in the bag by $\left(V_{s}\right.$ $\left.+V_{\text {Dbag }}\right) / V_{s}$, where $V_{s}$ is the volume of expired alveolar sample. $\mathrm{K}=$ factor to account for a change in $F_{2}$ due to absorption of carbon dioxide prior to the analysis ( $\$ 5.1$ ); it is usually assumed to be 1.05 . Anatomic or series deadspace is usually taken to be either $150 \mathrm{ml}$ [37] or 2.2 times body weight $(\mathrm{kg})$ [9].

\subsection{Reproducibility}

The coefficient of variation of a single measurement of transfer factor, including within day and between day variation, is approximately $5 \%$. The coefficients of variation of the component variables (alveolar volume and $K_{\mathrm{CO}}$ ) are respectively approximately $3.5 \%$ and $5.5 \%$ (table 2).

The better reproducibility of the transfer factor compared with its components is due to their being negatively correlated ( $\S 6.8)$. The result which is reported should be the mean of two determinations which meet the criteria for acceptability and which agree to within $10 \%$. The 
higher value should not be used because the cause of the variation is more likely to be technical than physiological. In this $T_{L}$ differs from the indices of forced expiratory flow discussed in [45]. The interval between the measurements should have been at least $4 \mathrm{~min}$ (see also $\S 6.4$ ). The coefficients of variation of $1 / D_{\mathrm{m}}$ and $1 / Q_{\mathrm{c}}$ are approximately $10 \%$ [48].

\section{Factors to be allowed for when calcu- lating and interpreting the result}

\subsection{Back tension of $\mathrm{CO}$}

\subsubsection{In mixed venous blood}

In heavy smokers and persons with a high occupational exposure to carbon monoxide, failure to allow for the $\mathrm{CO}$ back tension in mixed venous blood can lead to erroneously low values for $T_{\mathrm{L}}$ and its components. The error is avoided by using in equation 2 the mixed venous partial pressure and not the partial pressure in the pulmonary capillary blood, the $P_{\mathrm{v}, \mathrm{CO}}$. It is also inserted into equation 8 , where it is subtracted from the $\mathrm{CO}$ concentrations in both the numerator and the denominator of the term within the bracket. The CO back pressure is obtained by analysis of end tidal gas or peripheral venous blood. Measurement of alveolar carbon monoxide partial pressure is usually made after holding the breath for 20 $s$ [49]. The sensitivity of the method is increased by flushing the lungs with oxygen and then either holding the breath for as long as possible or rebreathing for $4 \mathrm{~min}$ via a $\mathrm{CO}_{2}$ absorber from a bag containing $4 \mathrm{l}$ of oxygen. An appropriate allowance should be made for the coexisting partial pressure of oxygen [9].

\subsubsection{In pulmonary capillary blood}

A transient back pressure of carbon monoxide in pulmonary capillary blood can artificially reduce the transfer factor in circumstances when the inspired concentration of carbon monoxide exceeds about $0.5 \%$. Thus the test concentration should not exceed $0.3 \%$; lower concentrations are acceptable provided appropriate allowance is made for the back pressure in mixed venous blood.

\subsection{Alveolar oxygen partial pressure}

The partial pressure of oxygen in the red cells contributes to the reaction rate of carbon monoxide with oxyhaemoglobin and hence influences the transfer factor (equation 7).

The capillary oxygen partial pressure is determined mainly by that in the alveolar gas $\left(P_{\mathrm{A}, 02}\right)$, so this quantity should either be standardized at or near its normal level $(14.5 \mathrm{kPa})$, or a correction made. A nearly constant oxygen pressure independent of the volume inspired is achieved by using a test gas mixture containing approximately $17-18 \%$ oxygen. A higher concentration (e.g. $21 \%$ ) is not recommended because the $P_{\mathrm{A}, 02}$ then varies with the volume of test gas which is inspired. Correction to a standard $P_{\mathrm{A}, 02}$ is done via measurement of $D_{\mathrm{m}}$ and $Q_{\mathrm{c}}$ (equation 7), or arithmetically, for which purpose it is convenient to assume a value for $D_{\mathrm{m}} / Q_{\mathrm{c}}$ [50]. The validity of the arithmetic correction for measurements made at altitude requires confirmation.

\subsection{Haemoglobin concentration}

An allowance should be made in circumstances when the concentration is outside the normal range. When $D_{\mathrm{m}}$ and $Q_{\text {c }}$ are known the correction is made using a version of equation 6 :

$$
1 / T_{\mathrm{L}}=1 / D_{\mathrm{m}}+1 /\left(\theta^{\prime} \cdot c_{\mathrm{Hb}} \cdot Q_{\mathrm{c}}\right)
$$

where $\theta^{\prime}$ is the reaction rate at the average normal haemoglobin concentration $\left(146 \mathrm{~g} \cdot l^{-1}\right)$ and $c_{\mathrm{Hb}}$ is the haemoglobin concentration as a fraction of normal. The units of the other variables are given above.

When the ratio $D_{\mathrm{m}} / Q_{\mathrm{c}}$ is known or may be assumed, the correction is as follows:

$$
T_{\mathrm{L}, \mathrm{s}}=T_{\mathrm{L}, \mathrm{obs}} \cdot\left(\mathrm{a}+\theta_{\mathrm{s}} \cdot c_{\mathrm{Hb}}\right) /\left[\left(\mathrm{a}+\theta_{\mathrm{s}}\right) \cdot c_{\mathrm{Hb}}\right]
$$

where $T_{\text {Lbs }}$ is the transfer factor at the subject's own haemoglobin concentration, $\theta_{\mathrm{s}}$ is the reaction rate at an oxygen pressure of $14.7 \mathrm{kPa}(110 \mathrm{mmHg})$ and haemoglobin concentration of $146 \mathrm{~g} \cdot l^{-1}\left(9 \mathrm{mmol} \cdot l^{-1}\right.$ of haemoglobin monomer), $c_{\mathrm{Hb}}$ is defined above and $\mathrm{a}$ is the ratio $D_{\mathrm{m}} / Q_{\mathrm{c}}$; values for this quantity in SI units ( $\mathrm{mmol}$, min and $\mathrm{kPa}$ ) of 230 , and in traditional units $(\mathrm{ml}$, min and $\mathrm{mmHg}$ ) of 0.7 , have been found to be satisfactory [ 50 , 51].

\subsection{Age, stature and body muscle}

The transfer factor is correlated positively with stature and with indices of body muscle (e.g. fat free mass divided by stature ${ }^{2}$ [52]; in adults it is correlated negatively with age. $K_{\mathrm{CO}}$ is negatively correlated with age. Due to changes associated with lung volume $(\S 6.6 .8) K_{\mathrm{CO}}$ is negatively correlated with stature [53].

\subsection{Habitual activity during adolescence}

Subjects having a high capacity for exercise or large lungs (including some asthmatics) often have a high transfer factor and $K_{\mathrm{CO}}[54,55]$.

\subsection{Smoking}

Smoking raises the back tension of carbon monoxide in the blood (§ 6.1). After allowing for back tension, smoking reduces the transfer factor both acutely [56] and in the long term [57]. The acute change, because it is 
reversible, may be due to an effect on $Q_{c}$. The chronic change is due in part to smoking contributing to the development of emphysema. However, the long term effect of smoking is already apparent in early adult life, though the respective contributions of the initial levels before taking up smoking, the age at which the transfer factor starts to decline, and the rate of decline thereafter, are incompletely understood [58]. The overall reduction in transfer factor due to smoking was reported in one series as being on average 1.8 SI units and 1.2 SI units in males and females respectively; intermediate levels were observed in ex-smokers [52].

\subsection{Posture and other factors} (see § 4)

\subsection{Lung volume}

Expansion of the lung leads to attenuation of the alveolar capillary membrane, flattening of alveolar capillaries and an increase in diameter of "comer vessels" between alveoli. As a result the transfer factor and $D_{\mathrm{m}}$ increase with lung volume, but $K_{\mathrm{co}}$ and $Q_{\mathrm{c}}$ diminish $[56,60]$.

The converse effects of lung volume on $T_{\mathrm{L}}$ and $K_{\mathrm{CO}}$ can contribute to the interpretation of an abnormal result. Examples include a patient with an increased total lung capacity which might be due to emphysema or to asthma, and a patient with a reduced total lung capacity which might be due mainly to pleural thickening or to asbestosis $(\S 1.3)$. In the former case the transfer factor and in the latter case the $K_{\mathrm{CO}}$ can contribute relatively more to the diagnosis than the other variables in isolation [9]. The method of estimating lung volume is not critically important, except in the presence of airway obstruction. This impairs lung mixing which in turn reduces $V_{\text {A,eff }}$ relative to $V_{\mathrm{A}}$; the resulting value for transfer factor $\left(T_{\mathrm{L}, \text { eff }}^{\mathrm{A} \text {,eff }}\right)$ is then reduced relative to $T_{\mathrm{L}}[60,61]$. In patients with airflow obstruction the neglect of this source of error can lead to the diagnosis of a transfer defect where none exists. The error is minimised by using $V_{\mathrm{A}}$, and in patients in whom the $\mathrm{FEV}_{1}$ is significantly reduced this is recommended for routine measurements. Alternatively if $V_{\mathrm{A}, \text { eff }}$ is used the patient can be fully bronchodilated prior to the measurement ( $\$ 5.4)$. $V_{\text {A,eff }}$ is recommended for occupational surveys when the proportion of subjects with material airflow obstruction is likely to be small.

\subsection{Ethnic group}

Ethnic group is often confounded with other factors which can affect the transfer factor. After these have been allowed for, the ethnic component of the transfer factor is small [54] and for clinical purposes unimportant. However, the total lung capacity relative to stature of many persons of African and Asian origin is small compared with Caucasians [64] and on this account the $K_{\mathrm{CO}}\left(T_{\mathrm{L}} /\right.$ $V_{\mathrm{A}}$ ) is increased [9].
Table 3. - Summary equations for total lung capacity and transfer factor for adults age 25-70 yr. The upper and lower percentiles are obtained by adding or subtracting the figure in the last column from the predicted mean.

\begin{tabular}{|c|c|c|}
\hline Index & Regression equation & 1.64.RSD \\
\hline & Men & \\
\hline$T_{\mathrm{L}, \mathrm{CO}, \mathrm{sb}}{ }^{1}$ & $11.11 \cdot \mathrm{H}-0.066 \cdot \mathrm{A}-6.03$ & 2.32 \\
\hline \multirow[t]{2}{*}{$\operatorname{TLC}(l)$} & 7.99·H - 7.08 & 1.15 \\
\hline & Women & \\
\hline$T_{\mathrm{L}, \mathrm{CO}, \mathrm{sb}}{ }^{\mathrm{f}}$ & $8.18 \cdot \mathrm{H}-0.049 \cdot \mathrm{A}-2.74$ & 1.92 \\
\hline $\operatorname{TLC}(l)$ & $6.60 \cdot \mathrm{H}-5.79$ & 0.99 \\
\hline
\end{tabular}

$1 \mathrm{mmol} \cdot \mathrm{min}^{-1} \cdot \mathrm{kPa}^{-1}$; H: standing height (m); A: age (yr); RSD: residual standard deviation. Between 18 and 25 yr: substitute 25 $\mathrm{yr}$ in the sequations. Reference values for $K_{\mathrm{CO}}$ can be obtained using a version of equation $4\left(K_{\mathrm{CO}}=T_{\mathrm{L}} / \mathrm{TLC}\right)[62,63]$.

\section{$7 \quad$ Reference values}

Reference values should ideally take into account gender, ethnic group and all the variables listed in the preceding section. In practice many of the variables are allowed for in the ways indicated in the text; the contribution of ethnic group is small $(\S 6.9)$ and the reference values are usually reported only with respect to age, stature and gender. Recommended reference values for Caucasian males and females are given in table 3. Those for $T_{\mathrm{L}}$ derive from studies carried out with equipment and techniques which seemed to be compatible with the recommended standards, and in which results were given for healthy nonsmokers. The equations are a summary of the mean from the literature; a detailed account of how they were derived has been given in the previous ECSC recommendations [64]. The corresponding values for $K_{\mathrm{CO}}$ were incompatible. In order to retain comparability with the other reference values $K_{\mathrm{CO}}$ should be calculated from $T_{\mathrm{L}}$ and TLC (table 3 ). The original material comprised only subjects of European descent aged 18-70 yr; the height range was $1.45-1.80 \mathrm{~m}$ in women, and $1.55-1.95$ $\mathrm{m}$ in men. The validity of the equations in table 3 is therefore in principle limited to that range. Between age $18-25 \mathrm{yr}$ and age of $25 \mathrm{yr}$ should be entered in the various equations, as cross-sectionally there is no change in that age range in nonsmokers. The upper 95 per cent or lower 5 per cent limit of predicted normal is obtained by adding or subtracting 1.64.RSD from the predicted mean. This is the preferred method of delineating a reference limit [64], rather than percent predicted, which is age dependent.

\section{Specification of equipment}

Gas analysis (see also $§ 5.2$ ).

The analysers should be checked for linearity by a serial dilution method, and for accuracy using a standard gas mixture.

Carbon monoxide

Infrared gas analyser: fractional concentration range 
$0-0.003$, accuracy $\pm 1 \%$. Alinearity of the analyser due to deterioration in the detector is a common problem in the measurements of $T_{\mathrm{L}}$ [65].

Helium

Katharometer: fractional concentration range $0-0.1$, accuracy $\pm 1 \%$. Allowance may need to be made for the coexisting concentration of oxygen if this differs between the inspired and expired gas samples; in practice the effect is small except when the measurement is made at a high oxygen concentration.

Oxygen

Paramagnetic analyser: fractional concentration range $0-1.0$, accuracy $\pm 1 \%$. A zero error due to misalignment of the detector is a common problem [65].

Response time

The response time of the analysers, should preferably not exceed $30 \mathrm{~s}$.

Automatic apparatus should meet the standards for volume, time and analytical accuracy which have been recommended.

The dead spaces of the inspirate and sample gas should be flushed with air and then emptied by suction prior to use. The analysers should be so arranged that the contents of both the inspiratory bag and the sample bag are analysed on each occasion. The deadspace of the valve box and mouth piece should be less than $0.1 l$ and the resistance to airflow at a flow of $6 \mathrm{l} \cdot \mathrm{s}^{-1}$ less than 0.15 $\mathrm{kPa} \cdot l^{-1} \cdot \mathrm{s}$ [37]. The system for detecting the stages in the breathholding manoeuvre should be independent of flow. The convention for calculating the breathholding time should be appropriate [39, 40, 42, 43], and the algorithm for calculating the results should make provision for $V_{\mathrm{A}}$ as well as $V_{\mathrm{A} \text {,eff }}$ and for the inclusion, when appropriate, of the mixed venous carbon monoxide tension. Not all apparatus in current use meet these criteria. The defects can give rise to systematic errors or bias in the presence of airflow obstruction.

\section{$9 \quad$ Future research}

Future research is required on a number of topics which are listed below.

\subsection{Improvements in methodology}

There is need for (a) a compact apparatus suitable for occupational surveys; (b) a rapid analyser for carbon monoxide (accuracy $2 \%$ ), response time $0.25 \mathrm{~s}$, which is also capable of analysing oxygen; (c) a new arithmetic model for describing $T_{\mathrm{L}}$ independent of lung volume, to replace $K_{\mathrm{CO}}\left(T_{\mathrm{L}}, V_{\mathrm{A}}\right)(c f \S 3.2)$

\subsection{Inter-laboratory differences}

Several studies have demonstrated material differences in the measurements of the transfer factor between laboratories. There is now an urgent need for operational research with a view to improving the standards of measurement.

\subsection{Additional reference values}

There is need for additional reference values for adolescents, women and old people. They should take into account age, stature, body muscle, smoking and habitual activity. The usefulness of the increase in transfer factor between rest and exercise for detecting early lung disease [66] also merits further investigation.

\section{Summary of recommendations}

\section{Which indices?}

Transfer factor should normally be measured by the single breathho'lding method using carbon monoxide as the principal test gas (hence $T_{\mathrm{LCO}, \mathrm{sb}}$ ). The result should be reported for the whole lung. The effect of smoking should be taken into account (see conditions below). If the blood haemoglobin is abnormal, $T_{\mathrm{L}}$ should be reported at a standard haemoglobin concentration (146 g. $l^{-1}$ and 136 $\mathrm{g} \cdot l^{-1}$ respectively for men and women). $V_{\mathrm{A}}$ should be reported at the same time ( $l$ BTPS).

\section{The test gas mixture}

The test inspirate should contain carbon monoxide in the fractional concentration $0.001-0.003$, an inert tracer gas (which is usually helium), and oxygen in the fractional concentration $0.17-0.18$. The gas analysers should be linear and accurate to $1 \%$ of the initial concentrations. Both the test inspirate and the alveolar sample should be analysed. The apparatus should conform to the specification given in $\S 8$.

\section{Conditions}

The subject should normally be rested and in a post absorptive state. Preferably there should have been no material exposure to carbon monoxide, for example from tobacco smoke or welding fumes on the day of the test. Where this is not the case the $\mathrm{CO}$ back pressure should be allowed for (e.g. in heavy smokers or when it is proposed to make more than 5 determinations of $T_{\mathrm{L}}$ in a single session).

\section{Procedure}

The test inspiration should start from residual volume and be completed within $4 \mathrm{~s}$. The volume inspired should be within $10 \%$ of the inspiratory vital capacity. The breathholding time should be $10 \pm 2 \mathrm{~s}$. The volume of washout prior to sample collection should be $0.75 l$, range $0.7-1.0 l$, and the sample volume $0.5-1.0 l$. Prior to sample collection the bag should have been flushed with air and then evacuated.

\section{Calculation}

The alveolar volume can comprise either the volume inspired plus the residual volume measured independently or the effective alveolar volume. When the latter is used 
in patients with reversible airflow obstruction a bronchodilator aerosol should preferably have been administered prior to the test. The effective time of breathholding should be taken to include two thirds of the time of inspiration and the time of expiration up to half way through the period of sample collection [40]. For this purpose the limits of inspiration can be defined visually or by extrapolating the middle linear part of the inspiratory limb of the spirogram. The back tension of carbon monoxide in the mixed venous blood should be assumed to be zero except when there has been a material exposure to carbon monoxide on the day of the test. An allowance for $P_{\mathrm{v}, \mathrm{CO}}$ should be made in regular heavy smokers and others who have smoked a cigarette within an hour of the test. The alveolar oxygen tension should be taken into account in measurements which are made at high altitude. The allowance for an abnormal haemoglobin concentration should be based on the relationship of Roughton and Forster ( $\S 6.3)$.

\section{Reference values}

Reference values should be based on age, stature and gender. Normally the results for nonsmokers will be used.

\section{References}

1. Borland CDR, Higenbottam TW. - A simultaneous single breath measurement of pulmonary diffusing capacity with nitric oxide and carbon monoxide. Eur Respir J 1989; 2: 5663.

2. Meyer M, Piiper J. - Nitric oxide (NO), a new test gas for study of alveolar capillary diffusion. Eur Respir J 1989; 2: 494-496.

3. Archer SL, Rist K, Nelson DP, DeMaster EG, Cowan N, Weir EK. - Comparison of the hemodynamic effects of nitric oxide and endothelium-dependent vasodilators in intact lungs. J Appl Physiol 1990; 68: 735-747.

4. Respiratory function tests in pneumoconiosis. Geneva International Labour Organisation. Occupational Safety and Health Series No. 6, 1966.

5. Thurlbeck WM, Henderson JA, Fraser RG, Bates DV. - Chronic obstructive Iung disease. Medicine 1970; 49: 81145.

6. Weitzman RG, Wilson AF. - Diffusing capacity and overall ventilation:perfusion in asthma. Amer J Med 1974; 57: $767-774$.

7. Morrison NJ, Abboud RT, Ramadan F, Miller RR, Gibson NN, Evans KG, et al. - Comparison of single breath carbon monoxide diffusing capacity and pressure-volume curves in detecting emphysema. Am Rev Respir Dis 1989; 139: 1179 1187.

8. Gould GA, Redpath AT, Ryan M, Warren PM, Best JJK, Flenley DC, et al. - Lung CT density correlates with measurements of airflow limitation and the diffusing capacity. Eur Respir J 1991; 4: 141-146.

9. Cotes JE. - Lung function: assessment and application in medicine, 5th Ed. Oxford, Blackwell Scientific Publications; 1993 , in press.

10. Greening AP, Hughes JMB. - Serial estimations of carbon monoxide diffusing capacity in intrapulmonary haemorrhage. $\mathrm{Cli}$ Sci 1981; 60: 507-512.
11. Wehr KL, Johnson RL Jr. - Maximal oxygen consumption in patients with lung disease. J Clin Invest 1976; 58: $880-890$.

12. Cotes JE, Zejda J, King B. - Lung function impairment as a guide to exercise limitation in work-related lung disorders. Am Rev Respir Dis 1988; 137: 1089-1093.

13. Becklake MR. - Asbestos related diseases of the lung and other organs: their epidemiology and implications for clinical practice. Am Rev Respir Dis 1976; 114: 187-227.

14. Cotes JE, King B. - Relationship of lung function to $\mathrm{X}$-ray reading (ILO) in patients with asbestos-related lung disorders. Thorax 1988; 43: 777-783.

15. Cormier Y, Belanger J, Tardif A, Leblanc P, Laviolette M. - Relationships between radiographic change, pulmonary function, and bronchoalveolar lavage in farmer's lung disease. Thorax 1986; 41: 28-33.

16. Craig DB, Donevan RE. - Mushroom worker's lung. Can Med Ass $J$ 1970; 102: 1289-1293.

17. Petro W, Muller E, Bergmann K-C, Unger U, Vogel J. - Impaired CO transfer factors in bird fancier's lung. Lung 1978; 155: 269-276.

18. Friend JAR, Palmer KNV, Gaddie J, Pickering CAC, Pepys J. - Extrinsic allergic alveolitis and contaminated cooling-water in a factory machine. Lancet $1977 ; 1: 297-300$. 19. DoPico GA, Rankin J, Chosy LW, Reddan WG, Barbee RA, Gee B, Dickie HA. - Respiratory tract disease from thermosetting resins. Ann Intern Med 1975; 83: 177-184.

20. Roughton FJW, Forster RE. - Relative importance of diffusion and chemical reaction rates in determining rate of exchange of gases in the human lung, with special reference to true diffusing capacity of pulmonary membrane and volume of blood in the lung capillaries. J Appl Physiol 1957; 11: 290 302.

21. Guénard H, Vuene N, Vaida P. - Determination of lung capillary blood volume and membrane diffusing capacity in man by the measurements of $\mathrm{NO}$ and $\mathrm{CO}$ transfer. Respir Physiol 1987; 70: 1113-1120.

22. Forster RE. - Diffusion of gases across the alveolar membrane. In: Farhi LF, Tenney SM, editors. The respiratory system. Section 3, Vol 4. Gas exchange. Bethesda; American Physiological Society. 1987: 71-88.

23. Forster RE, Fowler WS, Bates DV, Van Lingen B. - The absorption of carbon monoxide by the lungs during breathholding. J Clin Invest 1954; 33: 1135-1145.

24. Mitchell DM, Fleming J, Pinching AJ, Harris JRW, Moss FM, Veale D, Shaw RJ. - Pulmonary function in human immunodeficiency virus infection. A prospective 18-month study of serial lung function in 474 patients. Am Rev Respir Dis 1992, 146: 745-751.

25. Newth CJ, Cotton DJ, Nadel JA. - Pulmonary diffusing capacity measured at multiple intervals during a single exhalation in man. J Appl Physiol, 1977; 43: 617-625.

26. Kreukniet J. - Relation between rebreathing COdiffusing capacity of the lung and unequal ventilation. Scand J Respir Dis 1970; 51: 49-54.

27. Meyer M, Scheid P, Riepl G, Wagner H-J, Piiper J. Pulmonary diffusing capacities for $\mathrm{CO}_{2}$ and $\mathrm{CO}$ measured by a rebreathing technique. $J$ Appl Physiol 1981; 51: 1643-1650. 28. Bates DV. - Uptake of $\mathrm{CO}$ in health and emphysema. Clin Sci 1952; 11: 21-32.

29. Filley GF, MacIntosh DJ, Wright GW. - Carbon monoxide uptake and pulmonary diffusing capacity in normal subjects at rest and during exercise. $J$ Clin Invest 1954; 33: $530-539$.

30. Leathart GL. - Steady-state diffusing capacity determined by a simplified method. Thorax 1962;17: 302-307.

31. Lilienthal J Jr, Riley RL, Proemmel DD, Franke RE. 
- An experimental analysis in man of the oxygen pressure gradient from alveolar air to arterial blood during rest and exercise at sea level and at altitude. Am J Physiol 1946; 147: 199-216.

32. Rosenhamer GJ, Friesen WO, Mcllroy MB. - A bloodless method for measurement of diffusing capacity of the lungs for oxygen. J Appl Physiol 1971; 30: 603-610.

33. Wagner PD, Sutton JR, Reeves JT, Cymerman A, Groves BM, Malconian MK. - Operation Everest II. Pulmonary gas exchange during a simulated ascent of Mt. Everest. J Appl Physiol 1987; 63: 2348-2359.

34. Wagner PD. - Calculation of the distribution of ventilation-perfusion ratios from inert gas elimination data. Fed Proc 1982; 41: 136-139.

35. Adaro F, Meyer M, Sikand RS. - Rebreathing and single breath pulmonary $\mathrm{CO}$ diffusing capacity in man at rest and exercise studied by $\mathrm{C}^{18} \mathrm{O}$ isotope. Bull Eur Physiopathol Respir 1976; 12: 747-756.

36. Wright PH, Hanson A, Kreel L, Capel LH. - Respiratory function changes after asbestos pleurisy. Thorax 1980; 35: $31-36$.

37. American Thoracic Society. - Single breath carbon monoxide diffusing capacity (transfer factor). Am Rev Respir Dis 1987; 136: 1299-1307.

38. Chinn DJ, Harkawat R, Cotes JE. - Standardization of single-breath transfer factor $\left(T_{\mathrm{LCO}}\right)$; derivation of breathholding time. Eur Respir J 1992; 2: 492-496.

39. Graham BL, Mink JT, Cotton DJ. - Improved accuracy and precision of single breath $\mathrm{CO}$ diffusing capacity measurements. J Appl Physiol 1981; 51: 1306-1313.

40. Jones RS, Meade F. - A theoretical and experimental analysis of anomalies in the estimation of pulmonary diffusing capacity by the single breath method. $Q J$ Exp Physiol 1961; 46: 131-143.

41. Ogilvie CM, Forster RE, Blakemore WS, Morton JW. - A standardized breathholding technique for the clinical measurement of the diffusing capacity of the lung for carbon monoxide. J Clin Invest 1957; 36: 1-17.

42. Chinn DJ, Agnew J, Rowley L, Cotes JE. - Measurement technique influences the response of transfer factor $\left(T_{\mathrm{L}, \mathrm{CO}}\right)$ to salbutamol in patients with airflow limitation. Eur Respir $J$ 1988; 1: 15-21.

43. Crapo RO. - Effect of the method of measuring breathholding time on $T_{1}$ and $D_{1} / V_{\mathrm{A}}$ in normal subjects (abstract). Am Rev Respir Dis 1980; 121: suppl 331.

44. Ferris BG (principal investigator). - Epidemiology standardization project. Am Rev Respir Dis 1978; 118 (vol. 6, part. 2): $55-88$.

45. Quanjer PhH, Tammeling GJ, Cotes JE, Pedersen OF, Peslin R, Yernault JC. - Standardized lung function testing. Lung volumes and forced ventilatory flows. Report Working Party Standardization of Lung Function Tests ECSC and ERS. Eur Respir J 1993; 6: Suppl. 16: 4-39.

46. McGrath MW, Thomson ML. - The effect of age, body size and lung volume change on alveolar-capillary permeability and diffusing capacity in man. $J$ Physiol (London) 1959; 146: $572-582$.

47. Ashton I, Cotes JE, Holland P, Johnson GR, Legg SJ, Saunders MJ, White RG. - Acute effect of dibenz b.f.-1:4 oxazepine aerosol upon the lung function of healthy young men. J Physiol (London) 1918; 275: 85P.

48. Cotes JE, Hall AM. - The transfer factor for the lung; normal values in adults. In: Normal values for respiratory function in man. Editor: Arcangeli P. Torino: Panminerva Medica 1970: 327-343.

49. Jones RH, Ellicott MF, Cadigan JB, Gaensler EA. - The relationship between alveolar and blood carbon monoxide concentrations during breathholding. J Lab Clin Med April, 1958.

50. Cotes JE, Dabbs JM, Elwood PC, Hall AM, MacDonald A, Saunders MJ. - Iron deficiency anaemia: its effect on transfer factor for the lung (diffusing capacity) and ventilation and cardiac frequency during sub-maximal exercise. Clin Sci 1972; 42: 325-335.

51. Clark EH, Woods RL, Hughes JMB. - Effect of blood transfusion on the carbon monoxide transfer factor of the lung in man. Clin Sci 1978; 54: 627-631.

52. Cotes JE, Dabbs JM, Hall AM, Axford AT, Laurence KM. - Lung volumes, ventilatory capacity and transfer factor in healthy British boy and girl twins. Thorax 1973; 28: 709715.

53. Miller A, Thornton JC, Warshaw R, Anderson H, Teirstein AS, Selikoff IJ. - Single breath diffusing capacity in a representative sample of the population of Michigan, a large industrial state. Am Rev Respir Dis 1983; 127: 270-277.

54. Cotes JE. - Genetic and environmental determinants of the physiological response to exercise. In: Jokl E, Anand RL, Stoboy $\mathrm{H}$, editors. Advances in exercise physiology. Proc Internat Symp Exercise and Sports Physiology. Medicine and Sport 9: Basel: Karger, 1976: 188-202.

55. Weitzman PH, Wilson AF. - Diffusing capacity and over-all ventilation: perfusion in asthma. Amer J Med 1974; 57: 767-774.

56. Krumholz RA, Chavalier RB, Ross JC. - Changes in cardiopulmonary functions related to abstinence from smoking. Ann Intern Med 1965; 62: 197-207.

57. Knudson RJ, Kaltenborn WT, Burrows B. - The effects of cigarette smoking and smoking cessation on the carbon monoxide diffusing capacity of the lung in asymptomatic subjects. Am Rev Respir Dis 1989; 140: 645-651.

58. Hall AM, Heywood C, Cotes JE. - Lung function in healthy British women. Thorax 1979: 34: 359-365.

59. Cassidy SS, Ramanathan M, Rose GL, Johnson RL Jr. Hysteresis in the relation between diffusing capacity of the lung and lung volume. $J$ Appl Physiol 1980; 49: 566-570.

60. Cotes JE, Meade F, Saunders MJ. - Effect of volume inspired and manner of sampling the alveolar gas upon components of the transfer factor (diffusing capacity of the lung) by the single breath method. $J$ Physiol (London) 1965; 181; 73-75p.

61. Van Ganse W, Comhaire F, Van der Straeten M. - Alveolar volume and transfer factor determined by the single breath dilution of a test gas at various apnoea times. Scand $J$ Resp Dis 1970; 51: 82-92.

62. Love RG, Seaton A. - About the ECCS summary equations. Letter to the Editor. Eur Respir J 1990; 3: 489.

63. Quanjer $\mathrm{PhH}$. - About the ECCS summary equations. Reply to Dr. Love and Dr. Seaton. Eur Respir J 1990; 3: 490. 64. Quanjer $\mathrm{PhH}$ (ed.). - Standardized lung function testing. Bull Europ Physiopathol Respir 1983; 19: suppl 5, 1-95.

65. Chinn DJ, Naruse Y, Cotes JE. - Accuracy of gas analysis in lung function laboratories. Thorax 1986; 41: 133137.

66. Chu SS, Cotes JE. - Lung transfer and $K_{\mathrm{Co}}$ at cardiac frequency 100 beats/min as a guide to impaired function of lung parenchyma. Thorax 1984; 39; 524-528. 